\title{
OS BENEFÍCIOS QUE AS REUNIÕES DE SENSIBILIZAÇÃO DE OUVIDORIA TROUXERAM PARA A GESTÃO PARTICIPATIVA NO UNISL - CENTRO UNIVERSITÁRIO SÃO LUCAS
}

\author{
Marivanda Gonçalves da Conceição'
}

\begin{abstract}
Resumo
O objetivo deste artigo é demonstrar que, na gestão participativa do UniSL, a Ouvidoria estabelece um relacionamento com a comunidade acadêmica interna e externa, e para tal foi aplicado um trabalho de sensibilização através de reuniões, envolvendo todos os colaboradores do corpo administrativo, alunos, professores, coordenadores de graduação e pós-graduação, gestores e gerentes de setores da IES - Instituição de Ensino Superior, em que foi apresentado o objetivo da Ouvidoria do UniSL de informar a comunidade acadêmica interna e externa sobre o que é a Ouvidoria e sua missão, que é receber a comunidade acadêmica interna e externa, reconhecendo-a como sujeito pleno de direitos. A partir das sensibilizações, notou-se uma maior participação e o aumento das demandas feitas pela comunidade acadêmica com interesse em registrá-las, por ter conhecimento da existência e do papel ético desenvolvido pela Ouvidoria, que em muito tem contribuído para a resolução de problemas e a indicação de melhoria de serviços e processos.
\end{abstract}

Palavras-chave: Ouvidoria. Reuniões de Sensibilização de Ouvidoria. Comunidade Acadêmica Interna e Externa.

1 Licenciada em Letras - Português (Furg - Universidade Federal do Rio Grande/RS). Especialista em Metodologia do Ensino Superior (UniSL - Centro Universitário São Lucas). Mestre em Letras (Unir - Universidade Federal de Rondônia). Ouvidora do UniSL. (marivanda.goncalves@saolucas.edu.br) 


\begin{abstract}
The purpose of this article is to demonstrate that in the participatory management of UniSL, the Ombudsman's Office establishes a relationship with the internal and external academic community, and for this purpose, awareness-raising work was carried out through meetings involving all staff, professors, graduate and postgraduate coordinators, managers and sector managers of the HEI - Heigher Education Institution, which presented the objective of the UniSL Ombudsman's Office, which is to inform the internal and external academic community about the Ombudsman's Office and its mission, which is to receive the academic community internal and external, recognizing it as a full subject of rights. From the sensitization, it was noticed a greater participation and the increase of the demands made by the academic community with interest in registering their demands, for being aware of the existence and the ethical role developed by the Ombudsman's Office, which has contributed a lot to problem solving and indication of improvement of services and processes.
\end{abstract}

Keywords: Ombudsman. Ombudsman Awareness Meetings. Internal and External Academic Community. 


\section{INTRODUÇÃO}

Um modelo acadêmico eficiente é aquele que não somente garante resultados positivos nos indicadores de qualidade externos - como Enade, CPC (Conceito Preliminar de Curso), IGC (Índice Geral de Cursos), desempenho do exame da OAB -, alocação dos recursos financeiros e a qualidade do corpo de professores, mas que também garante resultados positivos nos indicadores internos, principalmente com a satisfação dos alunos e dos colaboradores.

O Brasil é um mercado grande em termos de Educação, um setor com aproximadamente 7,5 milhões de alunos. Mesmo com opiniões contrárias, a educação é uma prioridade e o governo tem tentado, de alguma forma, fazer com que a educação cresça na população de 18 a 25 anos, então, o primeiro fato importante é que o Brasil tem mais de 60 anos de expansão da educação superior privada e muitas vezes não lembramos disso, mas é uma trajetória longa e vemos outros países que ainda discutem essa questão. A segunda coisa importante é que, hoje, o Brasil é um país que já se adequou à questão da educação com fins lucrativos, então isso não é mais um tabu, e a terceira coisa importante é que quase $80 \%$ da educação superior no Brasil é privada, com as variações naturais entre regiões e estados da Federação. O Brasil tem criado inovações, algumas condições especiais que fazem com que a educação superior cresça em taxas aceleradas, podemos falar de Prouni, Fies, EAD, cursos para tecnólogos, que são coisas específicas do Brasil. Além disso, o Brasil tem um mercado competitivo, são mais de 2 mil instituições de ensino, com grupos regionais, escolas que estão avançando para o ensino superior, além dos fundos de investimentos, bancos e uma série de analistas olhando com muita atenção para esse mercado, o que nos faz refletir sobre um ponto importante: o Brasil é um país que tem um cenário favorável para o ensino superior, em especial o ensino superior privado.

E nesse cenário surgiu, em 2000, o UniSL - Centro Universitário São Lucas, uma instituição de educação e ensino superior, em Porto Velho, no estado de Rondônia. Após 18 anos de atuação, o Centro Universitário São Lucas oferece, atualmente, cursos reconhecidos pelo MEC e recebe acadêmicos de vários estados da Federação. Hoje, o Centro Universitário São Lucas consolida-se como o maior Centro Universitário privado do estado de Rondônia e um dos maiores da região Norte, o que aumenta o seu compromisso com a ética e com a responsabilidade social. A missão do Centro Universitário São Lucas consiste em estimular o desenvolvimento do conhecimento, das habilidades, dos talentos e das atitudes de seus alunos, para que atinjam a realização profissional, pessoal, social, além de se preparar para o exercício pleno da cidadania. Ao lado da tríplice missão de ministrar o ensino, estimular a pesquisa e promover a extensão, o UniSL não abdica de seu papel como centro de reflexão dos problemas do Brasil e do mundo e atua em áreas que possam conduzir à melhoria da qualidade de vida, estando inserido numa das regiões do país que apresentam índices de qualidade de vida que variam de regular a baixo.

E, como importante instrumento de controle social, a Ouvidoria do UniSL se configura como um espaço para o exercício da cidadania e da democracia. Diante disso, surge a necessidade de fazer um trabalho de conscientização através das sensibilizações, objeto de estudo deste artigo, para divulgar amplamente as formas de acesso, buscando incentivar a participação dos colaboradores administrativos, alunos, professores e demais integrantes da comunidade acadêmica interna, visando a melhoria da qualidade do ensino, pesquisa e extensão oferecidos pelo UniSL. 


\section{DESENVOLVIMENTO}

\subsection{A Ouvidoria do UniSL}

Como o UniSL é respeitado pelo seu público e tem como proposição uma gestão participativa, que ouve a comunidade acadêmica interna e externa, transformando-a em melhorias de serviços e processos, criação de novos serviços e incremento da qualidade do atendimento, o trabalho feito pela Ouvidoria estabelece um relacionamento com a comunidade fundamentado na transparência e no respeito. Este texto aborda, então, o modelo de Ouvidoria implantado no UniSL, cuja intenção é que as informações possam ajudar a comunidade a compreender o trabalho da Ouvidoria, bem como os benefícios que pode obter ao encaminhar suas sugestões, queixas, reclamações, elogios, consultas e denúncias.

A Ouvidoria do Centro Universitário São Lucas é uma unidade de apoio estratégico e pedagógico que concilia na busca de soluções de conflitos e incentiva mudanças de processos e serviços. Sempre atenta aos princípios de legalidade, impessoalidade e imparcialidade, a Ouvidoria é um veículo de comunicação autônomo e independente, alicerçada como ferramenta de participação da comunidade acadêmica, que busca defender os direitos individuais e coletivos para reduzir a judicialização. É por meio das manifestações que chegam através dos canais de acesso (e-mail, sistema online, telefone e atendimento presencial) que acontece o aperfeiçoamento de rotinas e processos de trabalho, além da melhoria da qualidade dos serviços prestados. A Ouvidoria aproxima a instituição da comunidade acadêmica de forma simples: levando a manifestação do demandante (comunidade acadêmica interna e externa) para a área responsável em busca de resolução. Por meio dos canais de acesso, qualquer pessoa consegue reclamar, denunciar, elogiar, sugerir, fazer consulta e pedir informação.

A Ouvidoria representa cada aluno, professor, colaborador administrativo, fornecedor, prestador de serviço do UniSL, das Clínicas e dos Ambulatórios, recebendo suas manifestações e monitorando-as até uma resposta final. Diferentemente dos demais canais de comunicação da instituição, a Ouvidoria recebe, avalia e dá encaminhamento às demandas, observando o sigilo de dados pessoais, quando solicitado, garantindo o DIREITO de resposta no menor prazo possível. A independência e a autonomia do Ouvidor garantem maior mobilidade e rapidez na busca de soluções. A comunidade acadêmica pode recorrer à Ouvidoria em caso de discriminações e violências decorrentes de orientação sexual, identidade de gênero, identificação religiosa, questões étnico-raciais ou qualquer manifestação de preconceito ou racismo.

É preciso salientar que, primeiramente, as demandas devem ser apresentadas às áreas de atendimento de primeiro nível, como a CEAL, Central de Atendimento ao Aluno, setor competente para a maioria dos atendimentos de rotina, como solicitação de documentos, negociação financeira, vistas de prova e pedido de segunda chamada. A Ouvidoria só deve "entrar em cena" se o demandante não obtiver resposta ou se sentir insatisfeito com o resultado encaminhado pelos canais de comunicação de atendimento de primeiro nível. A comunidade externa que precise se relacionar com o UniSL pode apresentar sua manifestação à Ouvidoria, que a recebe, analisa, trata e encaminha para a área responsável. Caso a questão não seja de competência da Ouvidoria, o manifestante é orientado quanto à forma mais adequada para o seu atendimento. 


\subsection{A Instituição da Ouvidoria do UniSL}

A Ouvidoria é o lugar onde colaborador, aluno, gestor, gerente, professor e comunidade externa podem fazer denúncias, reclamações, elogios, pedidos de informação ou sugestões sobre as atividades desenvolvidas pelo UniSL, com o objetivo de efetivar, aprimorar e aperfeiçoar os serviços oferecidos. Os atendimentos realizados pela Ouvidoria abrangem tanto o público interno do UniSL (colaboradores, alunos, contratados terceirizados e estagiários), quanto o público externo (população em geral). Ao receber cada manifestação, a Ouvidoria busca as respostas, informações, orientações e esclarecimentos necessários para o devido atendimento ao manifestante. A Ouvidoria funciona nas dependências do Centro Universitário São Lucas, com horário de atendimento presencial, e as manifestações podem ser realizadas através:

- Do sistema de Ouvidoria OMD, disponível no site do UniSL(http://saolucas.edu.br/ouvidoria).

- Do e-mail institucional: ouvidoria@saolucas.edu.br.

- Ligação telefônica através do número (69) 3211-8070.

- Atendimento presencial.

A instituição da Ouvidoria no UniSL é hoje uma realidade, e o Ouvidor é o responsável nominal por fazer girar processos comunicativos entre a instituição e a comunidade acadêmica. Tais processos constituem trocas de informações nas quais interesses conflitantes, aproximados ou coincidentes são interpretados, conciliados, negociados e conduzidos com vistas a um acordo que satisfaça as partes. Portanto o Ouvidor constitui-se numa figura representativa da instituição, com funções e atividades que têm por objetivo garantir o fluxo da comunicação. Valioso instrumento de marketing, a Ouvidoria visa também garantir os direitos da comunidade interna, os interesses dos fornecedores, o aumento da fidelização, a satisfação dos serviços prestados, além de servir de ponto estratégico para consultas sobre preferências, problemas de atendimento e necessidades de adequação tecnológica.

A Ouvidoria assume características de meio de comunicação, com recursos de produção e público-alvo. Entretanto, algumas Ouvidorias têm caráter fortemente político e um trabalho jurídico voltado para representar os interesses da instituição que a mantém. Por isso, é comum observar Ouvidorias que resistem às críticas e demandas, com o fim de defesa dos interesses da instituição. Tais Ouvidorias invertem a ordem natural, advogando para a instituição que representam. Por isso, torna-se necessário um estudo sobre as funções da Ouvidoria e um reposicionamento quanto às competências profissionais requeridas para o exercício do cargo.

\subsection{Estrutura Física da Ouvidoria do UniSL}

Do ponto de vista da estrutura física da Ouvidoria, para que o Ouvidor e a equipe desenvolvam suas atividades essenciais com confidencialidade, neutralidade e independência, além da postura comportamental, o espaço físico adotado é um local reservado, silencioso, que propicia concen- 
tração para o atendimento pessoal e telefônico, além da análise de mensagens virtuais. Esses cuidados são necessários para reforçar a confidencialidade e confiança. Entretanto, apesar de o espaço ser reservado, faz-se necessária boa divulgação virtual e/ou pessoal sobre sua localização, para que o espaço não seja confundido com espaço escondido. Sob o mesmo ponto de vista, em especial para manifestações de ordem interna, ou seja, dos colaboradores como manifestantes, o ambiente reservado proporciona maior segurança, conforto e confidencialidade. Um processo de comunicação assertivo e transparente fortalece a relação de confiança entre o UniSL e seu público-alvo, gera valor e proximidade nos relacionamentos, possibilitando que os conflitos sejam resolvidos na própria instituição.

\subsection{As Reuniões de Sensibilização de Ouvidoria no UNISL}

Para fomentar o relacionamento entre a comunidade interna e o UniSL, foi aplicado um trabalho de sensibilização envolvendo todos os colaboradores da IES por setores, iniciando com os gestores, seguidos dos funcionários administrativos, incluindo os jovens aprendizes, com demonstrações sobre a importância da Ouvidoria quanto aos reais benefícios para a instituição. Foram sensibilizados 460 colaboradores através de reuniões em que foi apresentado o objetivo da Ouvidoria do UniSL, que é informar a comunidade acadêmica sobre Ouvidoria e sua relação com clientes, fornecedores, colaboradores, comunidade e usuários dos serviços da instituição, assim como a missão, que é receber a comunidade, reconhecendo seus direitos. Assim, a Ouvidoria passa a ser percebida como agente de realização dos direitos da comunidade acadêmica dentro da instituição, intermediando e dialogando. Essa missão determina que a Ouvidoria do UniSL tenha foco no diálogo entre a comunidade e a instituição, garantindo que as manifestações contribuam para a melhoria da qualidade dos serviços prestados, bem como para o aperfeiçoamento da gestão.

As reuniões de sensibilização de Ouvidoria do UniSL geram grande expectativa na comunidade acadêmica interna, tanto para conhecer o papel da Ouvidoria de escutar de forma qualificada e profissional os que fazem parte da comunidade, quanto para ter um canal a fim de solucionar questões relacionadas ao seu dia a dia no trabalho. Nas reuniões fica clara a intenção de tornar aquele momento o primeiro passo em direção à busca e ao acesso à informação. A partir das reuniões, a comunidade acadêmica passa a compreender como é o fluxo de trabalho da Ouvidoria para obter respostas de suas solicitações em tempo breve.

Embora a porta de entrada para o atendimento sejam protocolos abertos na CEAL, onde todos fazem considerações e/ou solicitações, nas reuniões de sensibilização de Ouvidoria se dimensiona a importância de atender às solicitações de maneira rápida e objetiva. Nas sensibilizações foram feitos esclarecimentos sobre a Ouvidoria do UniSL e respondidos questionamentos e dúvidas, já que a Ouvidoria é um recurso que contribui para a avaliação e melhoria dos serviços prestados pela IES. A sensibilização funciona como uma reorganização para a prestação de um serviço de qualidade e contribui na busca da excelência.

As reuniões de sensibilização buscam valorizar a Ouvidoria, porque a falta de conscientização do papel do Ouvidor prejudica a execução dos atendimentos prestados. Dessa forma, é necessá- 
rio ressaltar que a Ouvidoria representa o UniSL e dá voz à comunidade acadêmica para propor melhorias, por meio dos atendimentos e das análises.

Após a sensibilização, uma vez esclarecidos os princípios e objetivos do trabalho da Ouvidoria e os benefícios que ela traz para a instituição, conseguimos uma adesão significativa da comunidade e consolidamos a ideia de que ela tem um espaço para solicitar informações, registrar sugestões, elogios, reclamações e denúncias, obtendo resposta ágil e resolutiva à sua manifestação.

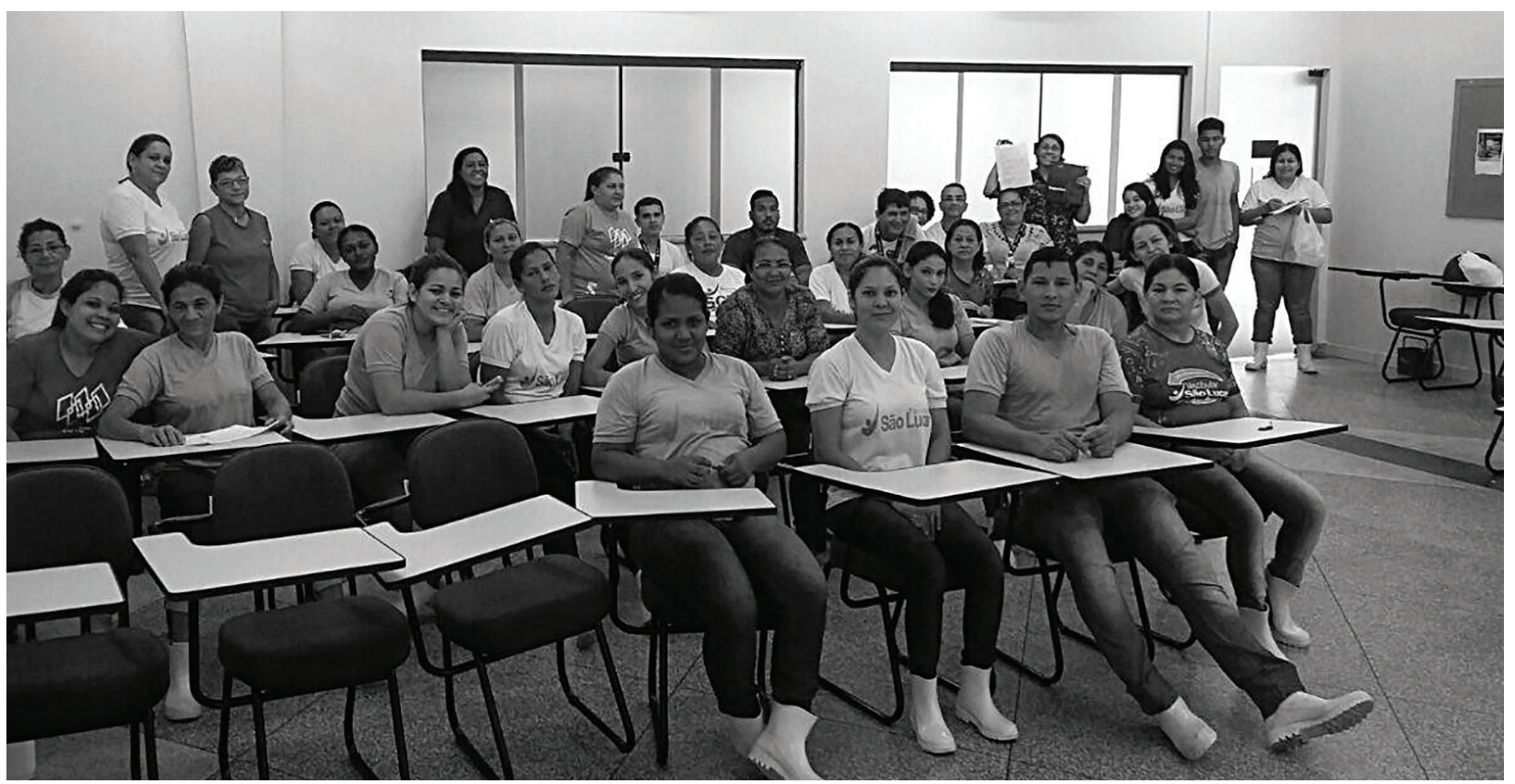

Parte da equipe do setor de limpeza do UniSL na reunião de sensibilização de Ouvidoria

\subsection{Importância da Sensibilização de Ouvidoria}

As reuniões de sensibilização envolveram todos os funcionários administrativos, alunos, professores, coordenadores de cursos de graduação e pós-graduação e gerentes de setor. O foco das palestras de sensibilização é na importância da Ouvidoria como ferramenta de gestão e sua importância para a consolidação da imagem do UniSL.

\subsubsection{Objetivos propostos para as sensibilizações}

- Fomentar o debate sobre a participação da Ouvidoria na gestão da instituição.

- Difundir as funções da Ouvidoria para a comunidade acadêmica interna e externa do UniSL.

- Sensibilizar sobre a importância e relevância da Ouvidoria para a melhoria de processos e serviços. 


\subsubsection{Organização das reuniões de sensibilização de Ouvidoria}

As sensibilizações foram divididas por setores e foi relatado o papel desempenhado pela Ouvidoria juntamente com as diretrizes apropriadas para potencializá-la como instrumento de qualificação dos serviços prestados à comunidade acadêmica, além do fato de que suas informações são bastante utilizadas pelos gestores na tomada de decisões a fim de promover melhorias nos processos, produtos ou serviços oferecidos pelo UniSL.

As sensibilizações abordam assuntos pertinentes ao dia a dia do trabalho, estimulando a troca de experiências entre os participantes, além do papel do Ouvidor, transparência, mediação, ética e cidadania.

As sensibilizações promovem a integração, amparadas pela imparcialidade e responsabilidade, e consolidam todos os serviços oferecidos pela Ouvidoria, uma importante ferramenta que serve como canal de participação da comunidade acadêmica interna e externa em relação à instituição, com destaque para as demandas de sugestões e críticas que são encaminhadas para a reitoria, após a triagem, na tentativa de solucionar o pedido do manifestante. A Ouvidoria é o canal direto entre os colaboradores e a reitoria do Centro Universitário São Lucas.

\subsection{Motivos para a Realização de Sensibilizações de Ouvidoria}

As reuniões de sensibilização são muito importantes para a comunicação e o relacionamento interpessoal dentro do Centro Universitário São Lucas. É nelas que se tem a oportunidade de tratar melhor os assuntos de interesse comum e onde cada um deve trazer seu ponto de vista e sua maneira de buscar a solução. As reuniões devem fazer parte da dinâmica da IES, visando o bom desempenho de toda a equipe em prol de seus ideais e também de sua satisfação.

As reuniões de sensibilização contribuem para o sucesso do UniSL ao definir metas da Ouvidoria, criar sinergia na equipe, manter todos informados em torno das decisões vindas das demandas da Ouvidoria, alimentar informações sobre o Centro Universitário São Lucas e criar estratégias.

\subsubsection{Por que estabelecer reuniões de sensibilização de Ouvidoria no UniSL?}

1. Integração da equipe do UniSL - Um contato mais próximo, em torno de um objetivo comum, onde todos tenham a oportunidade de se expressar e de ser ouvidos.

2. Participação na gestão da IES - A comunidade acadêmica ganha espaço para apresentar sugestões e de forma assertiva defender seu ponto de vista.

3. Desenvolvimentos individuais e da própria equipe - Uma reunião de sensibilização dinâmica e democrática, onde todos podem participar, apresentando sugestões e relatando soluções, além de outras informações que possam ser aplicadas no dia a dia de todos.

4. Comunicados da Ouvidoria - Os comunicados da Ouvidoria relativos à organização, dúvidas ou esclarecimentos sobre ela devem fazer parte da pauta das reuniões de sensibili- 
zação. Estes comunicados evitam boatos infundados e dúvidas por falta de comunicação.

5. Surgimento de ideias inovadoras - Nas reuniões, a comunidade acadêmica interna apresenta sugestões, questionamentos e esclarecimentos. Muitas ideias que surgem nas reuniões de sensibilização de Ouvidoria podem mudar a realidade da instituição. Podem ser apresentadas sugestões que aperfeiçoem não apenas o trabalho do manifestante, mas que possam ser adotadas por outros setores da organização.

6. Proximidade com a Reitoria - Essa proximidade facilita o cumprimento das metas e planejamentos estabelecidos.

7. Percepções do clima organizacional - As reuniões de sensibilização de Ouvidoria são uma oportunidade de perceber como está o clima organizacional.

\subsubsection{Passos para a organização de reuniões de sensibilização de Ouvidoria do UniSL}

\section{$1^{\circ}$ passo - Necessidade da reunião de sensibilização de Ouvidoria}

As reuniões de sensibilização são necessárias para divulgar o que é, para que serve e como deve ser usada a Ouvidoria pela comunidade acadêmica interna a fim de atingir desempenhos coletivos. Nesse caso deve se estabelecer os objetivos da sensibilização e os resultados a que se quer chegar, definir o número de participantes, fixar sua duração, hora e local.

\section{$2^{\circ}$ Passo - Preparação da reunião de sensibilização de Ouvidoria}

A reunião de sensibilização deve ser preparada. A preparação da sensibilização é um trabalho que pressupõe os seguintes princípios:

- Assegurar a organização do material e dos instrumentos de apoio.

- Estabelecer a lista de controle de presenças.

- Fixar com clareza os objetivos e os resultados a atingir.

- Elaborar uma pauta e enviar com o convite ou convocação a todos os participantes.

- Programar a condução de cada parte da reunião.

- Designar o elaborador da ata.

- Reservar a sala e marcar dia, hora e local para a sensibilização.

- Verificar o funcionamento dos equipamentos e preparação do material de apoio.

$3^{\circ}$ Passo - Ordem de trabalhos da reunião de sensibilização

- Descrever os objetivos e resultados a alcançar.

- Indicar os assuntos de cada etapa, com previsão da duração da reunião.

- Enviar convite ou convocação aos participantes.

- Motivar a participação da comunidade acadêmica. 
$4^{\circ}$ Passo - Convite ou convocação para a reunião de sensibilização de Ouvidoria

Da convocação ou convite deve constar informações sobre:

- Data e local da reunião de sensibilização de Ouvidoria.

- Hora de início e de conclusão da reunião de sensibilização.

\section{$5^{\circ}$ Passo - Abertura da reunião de sensibilização de Ouvidoria}

O Ouvidor deve:

- Iniciar a reunião na hora marcada, dar as boas-vindas e agradecer o tempo disponibilizado pelos participantes.

- Apresentar os objetivos da reunião de sensibilização e os resultados a que sequerchegar.

- Avisar que haverá ata, indicando previamente o secretário da reunião.

- Sublinhar a necessidade de ser conciso nas intervenções.

\section{$6^{\circ}$ Passo - Condução da reunião de sensibilização de Ouvidoria}

O Ouvidor é o elemento central para o sucesso da reunião, a ele compete:

- Congregar a atenção dos participantes e envolvê-los no clima da reunião.

- Facilitar a troca de pontos de vista e assegurar a participação de todos.

- Assegurar a organização das intervenções e a objetividade dos contributos.

- Gerir o tempo, evitando desvios na ordem dos trabalhos.

- Dinamizar a reunião, mostrando flexibilidade sobre tópicos controversos ou questões de difícil acordo.

- Mobilizar o máximo de opiniões para o espaço coletivo.

- Formular posições de consenso ou pedir a um dos participantes que apresente uma posição que reflita a posição do grupo.

- Sintetizar cada um dos pontos tratados, salientando os pontos de consenso e elencando os obstáculos apontados.

- Assegurar que sejam tomadas todas as decisões necessárias.

- Terminar com uma síntese dos resultados alcançados.

\section{$7^{\circ}$ Passo - Participação na reunião de sensibilização de Ouvidoria}

O desempenho do Ouvidor e dos participantes são os pilares do êxito da reunião de sensibilização de Ouvidoria.

\section{$8^{\circ}$ Passo - Conclusões e encerramento da reunião de sensibilização de Ouvidoria}

Cabe ao Ouvidor encerrar a reunião. Neste sentido importa:

- Sumariar as decisões tomadas, destacando os respectivos prazos. 
- Fazer o balanço dos aspectos positivos bem como das divergências evidenciadas e dos obstáculos a superar.

- Informar-se da elaboração da ata que constitui a memória escrita dos resultados e o guia para a futura monitorização e acompanhamento da execução das decisões.

- Concluir agradecendo a presença e a participação.

\section{$9^{\circ}$ Passo - Acompanhamento dos resultados da reunião de sensibilização de Ouvidoria}

- Assegurar que o secretário prepare a ata o mais cedo possível após a reunião.

- Enviar cópia da ata aos participantes com agradecimento pelos contributos.

- Remeter a todos os que estiveram na reunião e, se for o caso, a pessoas que não puderam comparecer, a ata definitiva da qual constem: decisões consensuais, conclusões assumidas e recomendações aceitas.

- Manter sempre os participantes informados.

Para a Ouvidoria, a reunião de sensibilização busca o envolvimento da comunidade acadêmica interna na construção da proposta avaliativa, pois sempre haverá novos alunos e colaboradores iniciando sua participação no processo: sejam estudantes, sejam membros do corpo docente ou técnico-administrativo.

\subsection{Resultados das Sensibilizações}

A Ouvidoria representa uma quebra de paradigmas que, em muitos casos, causa desconforto, principalmente para quem está habituado com práticas burocráticas dentro da instituição. Através da conscientização entre coordenadores pedagógicos, gerentes administrativos, líderes de setores, professores, diretores e alunos, pretende-se que a comunidade acadêmica compreenda a importância da Ouvidoria para o UniSL.

Como toda a instituição, o UniSL define sua Ouvidoria partindo de suas crenças, valores e princípios, com propostas de boas práticas que valorizam a confiança perante a comunidade acadêmica interna e externa. Percebe-se que, na relação entre a comunidade e a instituição, ainda há muito para ser construído, mas esse caminho é um grande desafio para a Ouvidoria que, por meio de compromissos e práticas adotadas pelos gestores, possibilita a harmonia nas relações, princípios e valores.

A partir das sensibilizações, nota-se o aumento das demandas feitas pelos colaboradores da instituição, que revelam que têm medo de procurar o DTH, Departamento de Talentos Humanos, por conta de retaliações, mas se sentem motivados a dar sugestões e que, agora, têm interesse em registrar suas demandas, por ter conhecimento da existência e do papel ético desenvolvido pela Ouvidoria. Portanto, a Ouvidoria se tornou uma "porta" para o registro de manifestações, as quais em muito têm contribuído para a resolução de problemas, além de servir como indicação para a 
melhoria de serviços e processos. Da mesma forma, os funcionários entenderam que a Ouvidoria do UniSL está regulada pelos princípios de transparência, imparcialidade e discrição em defesa dos direitos da comunidade acadêmica interna e externa, observando-se as normas e os regulamentos e garantindo que a comunidade tenha um atendimento atencioso, respeitoso e digno. Se a Ouvidoria do UniSL deve estar orientada por valores morais, legais e éticos para poder cumprir o seu papel, esses precisam estar definidos e serem divulgados para toda a comunidade acadêmica interna e externa.

E, neste contexto, a Ouvidoria do UniSL contribui para a imagem e reputação da instituição, pois trata-se de um sistema direto e exclusivo de relacionamento com a comunidade acadêmica, destinado a receber e dar tratativas aos manifestantes.

Também devemos destacar que a Ouvidoria do UniSL trabalha com as unidades da instituição, apurando as manifestações e transformando-as em melhorias para a qualidade dos fluxos de trabalho e atendimento. O comprometimento de todos é essencial para o sucesso da Ouvidoria, sendo importante que os colaboradores vejam como primordial o tratamento dado à comunidade acadêmica interna e externa, respeitando sua individualidade e estreitando o relacionamento.

Além disso, o envolvimento, a parceria e a interação possibilitam que as habilidades de cada unidade do UniSL sejam utilizadas para o benefício da instituição, ratificando assim o compromisso com a satisfação da comunidade acadêmica interna e externa, com a eficiência operacional e a qualidade dos serviços. Sendo assim, a Ouvidoria assegura o direito à livre expressão, estimulando o diálogo e zelando pelo cumprimento dos direitos da comunidade acadêmica.

\section{CONSIDERAÇÕES}

A busca pelo equilíbrio e harmonia nas relações evidencia o desafio assumido pelo UniSL para ampliar um diálogo com a comunidade acadêmica interna e externa, estabelecendo uma relação próxima, transparente e de confiança, que resulte em uma gestão participativa. A Ouvidoria do UniSL contribui para fortalecer esta relação através de um diálogo acolhedor, profissional, isento e imparcial, traduzindo as sugestões em melhorias. Da mesma forma, a intenção é conscientizar toda a comunidade acadêmica interna e externa, através das sensibilizações (alunos, professores, corpo técnico administrativo, prestadores de serviços terceirizados e comunidade externa em geral), a fim de incentivá-la a participar efetivamente das melhorias dos serviços prestados e poder contar com sua fidelidade e estímulo para trabalhar em prol do crescimento da empresa e da manutenção de bons resultados.

Vale destacar que, sendo a Ouvidoria do UniSL um agente de transformação, ela atua na busca de soluções sensibilizando os gestores e apoiando-os na tomada de decisão correta e de acordo com os direitos dos cidadãos. As práticas adotadas pela Ouvidoria do UniSL, na relação com a comunidade acadêmica interna e externa, fortalecem a imagem da instituição perante a sociedade, reduzem custos, promovem um ambiente de inovação, benefícios esses que levam a ABO - Associação Brasileira de Ouvidores a eleger a Ouvidoria como um benefício para as instituições, além de obter a adesão, a confiança e uma postura colaborativa dos funcionários. 


\section{REFERÊNCIAS}

ALVES JÚNIOR, Mário Nelson. A contribuição estratégica das Ouvidorias para melhoria dos serviços prestados pelas organizações: um estudo de caso na Secretaria de Estado e Saúde de Santa Catarina. Florianópolis, 2012.

LIMA, Alessandra Rodrigues de Almeida. Boas práticas na Ouvidoria do SUS do estado de Goiás. Disponível em: http://www.sgc.goias.gov.br/upload/arquivos/2014-09/boas-praticas-na-ouvidoria-do-sus-do-estado-de-goiAs1.pdf

ROMAN, Artur. Ouvidoria Interna: lugar de comunicação para os não ditos revelados. Porto Alegre: Salinas, 2012.

VISMONA, E. L.; BARREIRO, A. E. A (Org.) Ouvidoria Brasileira: o cidadão e as instituições. São Paulo: Associação Brasileira de Ouvidores, 2015. 